\title{
Complex Methods in Economics: An Example of Behavioral Heterogeneity in House Prices*
}

\author{
Wilko Bolt, Maria Demertzis, Cees Diks, Marco van der Leij ${ }^{\dagger}$
}

December 19, 2011

\begin{abstract}
We show how simple statistical techniques for capturing critical transitions used in natural sciences, fail to capture economic regime shifts. This implies that we need to use model-based approaches to identify critical transitions. We apply a heterogenous agents model in a standard housing market model to show that these family of models generate non-linear responses that can capture such transitions. We estimate this model for the United States and the Netherlands and find that first, the data does capture the heterogeneity in expectations and, second, that the qualitative predictions of such nonlinear models are very different to standard linear benchmarks. It would be important to identify which approach can serve best as an early warning indicator.
\end{abstract}

Keywords: critical transitions, heterogenous agents model, bounded rationality, housing prices

JEL Classification: C53, R21, R31

\section{Introduction}

The magnitude of the recent financial crisis and the fact that it has caught most of the economics profession by surprise is an indication that the tools we have in our hands do not

*Views expressed are our own and do not reflect those of the institutions with which we are affiliated. We are grateful to Vincent Sterk as well as participants at the 14th DNB Annual Conference 2011 on "Complex Systems: Towards a better understanding of financial stability and crises" for comments and suggestions. Supported by Spanish Ministry of Science and Education grant SEJ2007-62656 and by the Netherlands Organisation for Scientific Research (NWO) under the Complexity program. The usual disclaimer applies.

${ }^{\dagger}$ Corresponding author: m.demertzis@dnb.nl; w.bolt@dnb.nl, Research Department, De Nederlandsche Bank, PO Box 98, 1000 AB Amsterdam, The Netherlands; C.G.H.Diks@uva.nl, M.J.vanderLeij@uva.nl, Department of Economics, CeNDEF, University of Amsterdam, Valckenierstraat 65-67, 1018 XE Amsterdam, The Netherlands. 

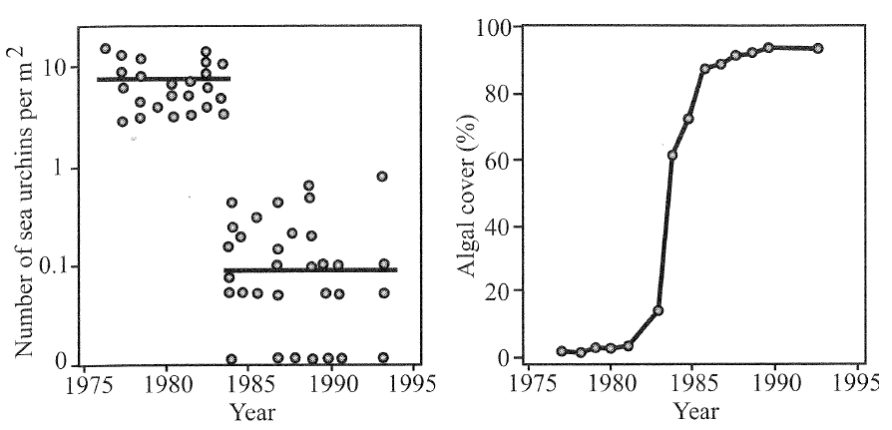

Figure 1: Number of sea urchins per $m^{2}$ (left panel) and the percentage of algal cover (right panel). Reproduced from Scheffer (2009).

necessarily help us identify the weaknesses in the system. This implies that to the extent that we have early warning systems, they do not work well in terms of predicting abrupt changes. These tools are typically linear in nature, and recently efforts have concentrated in borrowing techniques from the natural sciences which acknowledge the complexity, non-linearities, of the underlying systems. ${ }^{1}$ Complex methods capture such abrupt changes, which are identified with critical transitions in natural sciences. One example given by Scheffer (2009) is the 1983/1984 Caribbean coral reef collapse. This was associated with a sudden collapse in the number of sea urchins on the sea floor, which caused a sudden increase of algal cover. This is illustrated in Fig. 1.

A second example of a critical transition mentioned by Scheffer (2009) is the birth of the Sahara desert. The sudden desertification of the Sahara desert, around 5,500 years ago, is believed to be the result of slowly changing insolation, which in turn was due to slow changes in the angle of the Earth's axis of rotation with respect to the sun. As depicted in Fig. 2, this gradual change in insolation drove the system to a tipping point, resulting in an abrupt shift in climate and vegetation cover over the Sahara.

The question that arises from this is whether the series themselves exhibit properties around the time these transitions happen and therefore pre-announce their occurrence. Scheffer (2009) and Scheffer et al. (2009) argue that around these moments, time series are characterized by a critical slowing down in terms of pace. This implies that the system's memory increases, and that it recovers more slowly from shocks. An important advantage of such a technique would be its a-theoretical nature. No views about what drives the state of the variable would have to be imposed in order to identify this critical slow down. We will see however, that the conditions allowing for such an a-theoretical early warning are very stringent and that when applied to either stock market data (high frequency) or more traditional macro

\footnotetext{
${ }^{1}$ See the opening address to the ECB Central Banking Conference on 18 November 2010, by the ECB President, Jean-Claude Trichet where he said that "in the face of the crisis, we felt abandoned by conventional tools", and called for the development of complex systems based approaches to augment existing ways of understanding the economy.
} 

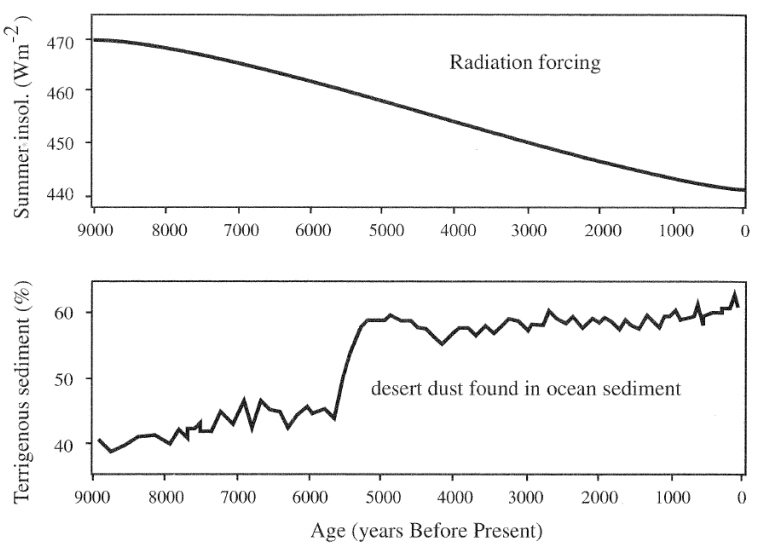

Figure 2: Summer insolation (top panel) and desert dust sedimentation in the ocean in front of the west-African coast (bottom panel). Reproduced from Scheffer (2009).

series like housing prices (low frequency), they do not appear to work well. Ditlevsen and Johnsen (2010) and Thompson and Sieber (2011) provide compelling arguments why Scheffer's a-theoretical approach may fail in the presence of noise, as the noise may induce early transitions before a slowdown can be detected.

This implies that a-theoretical methods do not work very well in terms of identifying points in time around which the system is about to acquire very different properties. We then need to turn to methods that allow for the existence of multiple equilibria and identify the conditions under which they prevail. Fig. 3 shows how a system can move from single to multiple equilibria as conditions ( $y$-axis) change, but it also shows how equilibria can be both stable as well as unstable, depending on the value of a bifurcation parameter. In what follows, we will show how these dynamics can be illustrative of the market for housing in the US and the Netherlands. In order to do this, we have to abandon the a-theoretical methods and make some assumptions about key variables in the markets. Heterogenous agents models (HAMs) are one way of imposing behavioral assumptions on a specific market, that will allow for non-linear responses and which can lead to the types of dynamics described in Fig. 3.

Our paper is organized as follows. Section 2 briefly describes the shortcomings of existing early warning indicators. It then outlines the a-theoretical criteria that Scheffer et al. (2009) describe to capture critical transitions in the natural sciences. We then show a number of examples with applications to stock market data where, although visible to the naked eye, critical transitions cannot be captured by these techniques. Section 3 then turns to a modelbased approach, based on heterogenous agents models (HAMs), to capturing these dynamics. We describe first a traditional housing price model. We then borrow an application of the HAMs methodology from Boswijk et al. (2007), and apply it on the housing market. In Section 4 we then take the implied model to the data and discuss the results for the US and the Netherlands. Section 5 summarizes the conclusions and discusses how this methodology 


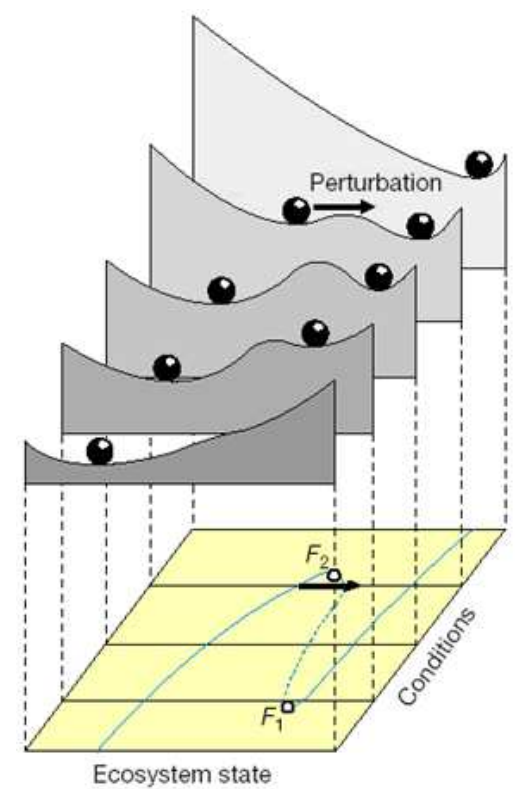

Figure 3: Bifurcation diagram. Reproduced from Scheffer (2009).

can contribute to policy making.

\section{Early Warning Systems for financial crises}

The clean-up cost of the financial crisis was estimated by the IMF to be 11.9 trillion US dollars ( $\$ 1800,-$ per every adult and child on the planet). Numerous attempts have been made to develop systems that can detect underlying instabilities in the economic system, commonly referred to as Early Warning Systems (EWSs). Traditionally, the approach to developing EWSs consists of a number of steps. First, provide an operational definition of a crisis (banking, currency, sovereign debt, liquidity). Second, identify one or more key economic and/or financial variables to monitor over time. Third, define when an alarm is raised, either when these variables exceed certain threshold values or when measures that capture the probability of a certain event happening in a given horizon exceeds permissible levels. Several approaches exist in the literature: the signal approach (Kaminsky et al., 1998), binomial/multinomial logit/probit models (e.g. Demirgüç-Kunt and Detragiache, 2005), binary recursive trees (e.g. Davis and Karim, 2008) or Markov switching models for currency crises (Abiad 1999; Arias and Erlandsson, 2005). Although these models provide significant in-sample explanatory power, in that some or more of their parameters are significant, they have poor out-of-sample predictive ability (Berg et al., 1999, 2005; Davis and Karim, 2008). A possible explanation for this might be that a linear logit/probit type of regression approach ignores several important issues. These range from ignoring nonlinear effects, (Berg and Patillo, 1999; Kaminsky et al., 
1998) failing to acknowledge that a panel data approach can only be valid when different crises (across countries and time) are universally caused by identical factors, Van den Berg et al. (2008) or have identical dynamics, neither of which is true in practice. Last, crises incorporate important self-fulfilling elements implying that they can occur very quickly and before there is a significant long-term deterioration in economic fundamentals (Oh et al., 2006).

A complex systems approach put forward by Scheffer et al. in the Sept. 2009 issue of Nature, summarizes the statistical properties of the system prior to transitions as follows: around that point, the system exhibits slower recovery from perturbations. As the system slows down before it changes equilibrium, the intrinsic rates of change decrease and the system recovers slower from shocks. This implies an increase in the 'memory' and they show that this is captured with both an increase in the variance of the variable as well as its autocorrelation. We have estimated the time-varying autocorrelation and variance for a number of stock market data (Figs 17-18 in the Appendix). These figures plot the original series (stock market index), the log return and then the time-varying standard deviations as well as the AR(1) coefficient, calculated for two different windows (20 and 60 days). The picture that emerges is similar in most series that we have tried. Take Fig. 17 (upper panel) which refers to the S\&P 500 index. The series shows the 1987 crash when the index has a clear break in its value. The value of the standard deviation is indeed increasing for a period before the crisis but it is not higher than previous peaks. At the same time, the $\mathrm{AR}(1)$ coefficient is very far from the value of one associated with the assumed high autocorrelation. The same can bee seen for the dotcom bubble burst (Fig. 17, lower panel), the Hang Seng index during the Asian crisis (Fig. 18, upper panel) or the S\&P500 after the collapse of Lehman Brothers (Fig. 18, lower panel). There maybe a number of reasons why these techniques are not successful in capturing important changes. First, they are designed for smooth differential equations that are deterministic in nature. Instead, economic series are governed by stochastic movements that may blur the power of these measures. Second, there is an important role of self-fulfillment in economic series unlike those in the natural sciences. Both of these would imply that series would already tip from one state to the other some time before the statistics were allowed to take the values indicated by the techniques.

\section{Heterogeneous beliefs and the Housing Market}

As purely statistical measures do not identify critical transitions, we turn next to a modelbased approach. We will apply a model, based on Brock and Hommes (1997, 1998), in which agents have heterogenous beliefs. In this class of models agents are boundedly rational and have different views about the future values of key variables. At the same time, their beliefs are allowed to switch from one period to the next between a number of strategies available, based 
on how well they have done in the past (forecast error). The advantage of such techniques is that they allow for endogenous dynamics to be at play, and do not preclude the fact that even if systems are globally stable, they maybe locally unstable for values of parameters that are economically meaningful. Such models have been widely used in the finance literature (see Boswijk, Hommes and Manzan (2007) for an application but also a comprehensive summary of the literature) and are only beginning to enter the macro field, which has been very reluctant to allow for bounded rational agents. In what follows we will apply heterogeneity of agents on a traditional housing price model. ${ }^{2}$ The housing market is of particular relevance as it is an important contributor to growth and acts as a leading indicator for the business cycle (Leamer 2007). Also, since housing markets are known to be subject to booms and busts, allowing for non-linear responses is of particular relevance. Based on a standard model for housing prices, we will begin with identifying what affects the annual cost of housing, also known as the imputed rent, $H_{t}$. This is the sum of a number of variables, based on Himmelberg et al., (2005) shown below:

$$
H_{t}=P_{t} r_{t}^{r f}+P_{t} \omega_{t}-P_{t} q_{t+1}-P_{t} \gamma_{t}
$$

Let $P_{t}$ denote the price for one unit of housing at time $t$. The first component is the cost of foregone interest that the homeowner would have earned by investing in something other than a house, calculated as the price of housing $P_{t}$ times the risk-free interest rate $r_{t}^{r f}$. The second term represents the one-year cost of such things as property taxes minus tax deductability, and maintenance costs. The third term, $P_{t} q_{t+1}$, is the expected capital gain (or loss) during the year, and the fourth term, $P_{t} \gamma_{h, t}$, represents an additional risk premium to compensate homeowners for the higher risk of owning versus renting. Following the no arbitrage condition, one year rent must equal the sum of the annual cost of renting $\left(Q_{t}\right)$. We can therefore substitute $H_{t}$ with $Q_{t}$, the actual cost of renting, where the capital gain is now calculated as this period's realization, vis-á-vis last period.

\subsection{The housing market model}

Boswijk, Hommes and Manzan (2007) (BHM hereafter) proposed an agent-based model for stock prices, which we apply here in the context of the housing market. A similar exercise, although theoretical only, is done by Burnside et al. (2011). Their approach has two important differences. First, agents disagree about the fundamental value of housing, whereas we assume that agents agree about the fundamental value of houses but disagree about how prices return to it. Second, their model is epidemiological in nature, in that agents infect each other. In our approach, agents are simple optimizers who rely on past performance to evaluate and revise

\footnotetext{
${ }^{2}$ For a similar exercise see also Kouwenberg and Zwinkels (2011).
} 
their beliefs. We assume two types of agents $h \in\{1,2\}$. Assume that the demand for housing of individuals can be represented by a continuous variable, measuring the number of units of housing demanded. Based on the equation for imputed rents, actual rents are equal to:

$$
Q_{t}=P_{t}\left(r_{t}^{r f}+\omega_{t}\right)-P_{t} q_{t}-P_{t} \gamma_{t}
$$

where $q_{t}=\frac{P_{t}}{P_{t-1}}-1$ is the actual capital gain. As already mentioned, the variable $P_{t} \gamma_{t}$ represents the additional risk premium to compensate houseowners for the higher risk of owning versus renting. We interpret $\gamma_{t}$ to be the excess return on housing, $\gamma_{t}=R_{t}$ such that by rearranging (2) and leading one period, we then have the definition of $R$ (see also Ambrose et al. 2011, Campbell et al., 2009):

$$
R_{t+1}=\frac{P_{t+1}+Q_{t+1}}{P_{t}}-\left(1+r_{t+1}\right)
$$

where $r_{t+1}=r_{t+1}^{r f}+\omega_{t+1}$ assumed here to be constant $(r)$ for simplicity. The demand, $z_{h, t}$, of agents of belief type $h$ is determined by maximizing one-period ahead excess returns adjusted for risk:

$$
E_{h, t}\left(R_{t+1} z_{h, t}\right)-a \operatorname{Var}_{h, t}\left(R_{t+1} z_{h, t}\right),
$$

where $a$ is a measure of risk aversion.

Agents are assumed to be homogeneous with respect to their expectations regarding the variance, that is, $\operatorname{Var}_{h, t}\left(\left(P_{t+1}+Q_{t+1}\right) / P_{t}-(1+r)\right)=V_{t}$, while they are heterogeneous concerning their expectations of excess return $E_{h, t}\left(\left(P_{t+1}+Q_{t+1}\right) / P_{t}-(1+r)\right)$. For simplicity, we also assume $V_{t}$ to be constant over time: $V_{t}=V$. Maximizing Eq. (3) leads to the demand for housing:

$$
z_{h, t}=\frac{E_{h, t}\left(P_{t+1}+Q_{t+1}\right) / P_{t}-(1+r)}{a V}
$$

of agents of type $h$.

Upon aggregation of the demand across these two types of agents, the market clearing condition is:

$$
\sum_{h=1}^{2} \frac{n_{h, t}\left(E_{h, t}\left(P_{t+1}+Q_{t+1}\right) / P_{t}-(1+r)\right)}{a V}=S,
$$

where $S$ is the stock of housing, assumed to be constant, and $n_{h, t}$ is the fraction of agents in every period that have expectation of type $h .^{3}$

\footnotetext{
${ }^{3}$ We assume that $S$ is large enough, such that neither type has an incentive to sell short on houses.
} 
Solution 1 Solving the market clearing condition leads to the following price equation:

$$
(1+r+\alpha) P_{t}=\sum_{h=1}^{2} n_{h, t} E_{h, t}\left(P_{t+1}+Q_{t+1}\right)
$$

where $\alpha=a V \times S$.

Following BHM, we assume that the fundamental process underlying the model, i.e. $Q_{t}$, follows a geometric Brownian motion with drift, i.e.:

$$
\log Q_{t+1}=\mu+\log Q_{t}+v_{t+1}, \quad\left\{v_{t}\right\} \stackrel{\text { i.i.d. }}{\sim} N\left(0, \sigma_{v}^{2}\right)
$$

from which we obtain:

$$
\frac{Q_{t+1}}{Q_{t}}=(1+g) \varepsilon_{t+1},
$$

with $g=e^{\mu+\frac{1}{2} \sigma_{v}^{2}}-1$ and $\varepsilon_{t+1}=e^{v_{t+1}-\frac{1}{2} \sigma_{v}^{2}}$, such that $E_{t}\left(\varepsilon_{t+1}\right)=1$.

We define the fundamental price as the price that would prevail under rational expectations $E_{t}\left(R_{t+1}\right)$ about the conditional mean of $R_{t}$, while expectations regarding the conditional variance are again constant: $\operatorname{Var}_{h, t}\left(R_{t+1}\right)=V$. Note that $V$ may, but need not, correspond to the actual conditional variance. The present definition is convenient, as it is the equilibrium price around which the market prices will fluctuate; it is the market price that would prevail if agents have correct expectations about the first conditional moment, regardless of whether their beliefs regarding the conditional variance are also correct. Under rational expectations on the first conditional moment, we can re-write the price equations (5):

$$
(1+r+\alpha) P_{t}=E_{t}\left(P_{t+1}+Q_{t+1}\right)
$$

Solution 2 By applying the law of iterated expectations and imposing the transversality condition, we obtain the fundamental price solution:

$$
\tilde{P}_{t}=E_{t}\left[\sum_{i=1}^{\infty} \frac{Q_{t+i}}{(1+r+\alpha)^{i}}\right]=\sum_{i=1}^{\infty} \frac{(1+g)^{i} Q_{t}}{(1+r+\alpha)^{i}}=\frac{1+g}{r+\alpha-g} Q_{t}, \quad r+\alpha>g
$$

Definition 3 We define, $X_{t}=\frac{P_{t}}{\tilde{P}_{t}}-1$, the price relative to its fundamental.

Solution 4 It follows that the price equation (5) simplifies to:

$$
X_{t}=\frac{1}{\Upsilon} \sum_{h=1}^{2} n_{h, t} E_{h, t}\left(X_{t+1}\right)
$$


where $\Upsilon=(1+r+\alpha) /(1+g)$ is the discount factor, which depends on the underlying parameters of the model.

\subsection{Two types of agents}

Following Boswijk, Hommes and Manzan (2007) we assume that each of the two types of agents have $\operatorname{AR}(1)$ type beliefs about $X_{t+1}$, but with different values of $\phi$ :

$$
\begin{aligned}
& E_{1, t}\left(X_{t+1}\right)=\theta+\phi_{1} X_{t-1} \\
& E_{2, t}\left(X_{t+1}\right)=\theta+\phi_{2} X_{t-1}
\end{aligned}
$$

where $\phi_{1} \neq \phi_{2}$. The parameter $\theta$ represents a bias in the individuals' expectations and for simplicity we assume it to be the same for both types of agents.

Note that homogeneous beliefs, $\phi_{1}=\phi_{2}<\Upsilon$, would lead to the price converging to the fundamental price, whereas homogeneous beliefs $\phi_{1}=\phi_{2}>\Upsilon$ would imply a bubble, where prices would deviate more and more from the fundamental price. ${ }^{4}$ If one of the belief parameters, $\phi_{1}$ say, is smaller than $\Upsilon$, and the other, $\phi_{2}$, larger than $\Upsilon$, the fractions of agents being of belief type 1 or 2 , determine whether prices are temporarily converging to the fundamental price or diverging. Since agents are allowed to switch between the two different types of beliefs, the fractions themselves are changing over time. This in turn implies that the system may temporarily be in a bubble regime, where prices deviate further from fundamentals, or in a correction regime, with prices converging back to the fundamental.

The switching between the two types of beliefs is based on the recent past performance of the strategies, measured in terms of realized profits, $\pi_{h, t-1}$.

Definition 5 We define realized profits as follows:

$$
\begin{aligned}
\pi_{h, t-1} & =\left(X_{t-1}-\Upsilon X_{t-2}\right) z_{h, t-2} \\
& =\text { cnst. } \times\left(X_{t-1}-\Upsilon X_{t-2}\right)\left(\phi_{1} X_{t-3}-\Upsilon X_{t-2}\right)
\end{aligned}
$$

The fractions are determined by a logistic switching model with a-synchronous updating:

$$
\begin{aligned}
n_{1, t} & =(1-\delta) n_{1, t-1}+\delta \frac{e^{\beta \pi_{1, t-1}}}{e^{\beta \pi_{1, t-1}}+e^{\beta \pi_{2, t-1}}} \\
& =(1-\delta) n_{1, t-1}+\delta \frac{1}{1+e^{-\beta\left(X_{t-1}-\Upsilon X_{t-2}\right)\left(\phi_{1}-\phi_{2}\right) X_{t-3}}} \\
n_{2, t} & =1-n_{1, t} .
\end{aligned}
$$

\footnotetext{
${ }^{4} \mathrm{~A}$ house price bubble occurs when agents have unreasonably high expectations about future capital gains, leading them to perceive their user cost to be lower than it actually is and thus pay "too much" to purchase a house today.
} 
The term a-synchronous updating refers to the fact that only a fraction $\delta$ of agents reevaluates and updates beliefs according to the logit model in each given period. ${ }^{5}$ Parameter $\beta$, referred to as the intensity of choice, represents the sensitivity of agents' way of updating with respect to small changes in past performance $\pi_{h, t-1}$.

We estimate the model in two steps: first we estimate the deviations of prices from their fundamental value, $\left\{X_{t}\right\}$, using housing prices, and rents. ${ }^{6}$ Second we use the estimated deviations to estimate the agent-based model, through minimizing the sum of squared insample forecast errors:

$$
S S E=\sum_{t=1}^{T}\left(X_{t}-\frac{\phi_{1} n_{1, t} X_{t-2}+\phi_{2} n_{2, t} X_{t-2}+\theta}{\Upsilon}\right)^{2}
$$

where $n_{h, t}$ depends on past prices, and parameters $\phi_{1}, \phi_{2}, \beta, \delta$ and $\Upsilon$, as described above. As the dependence of $n_{h, t}$ on the model parameters is nonlinear, the estimation is performed using nonlinear OLS.

\subsection{Local stability result}

Before turning to the results we present a simulation, by means of an example, in which we show how our model can show a bifurcation at which the fundamental price changes from being locally stable to locally unstable. We consider the example where $\theta=0$, i.e. there is no bias in the individuals' expectations. The system is locally stable if the following condition holds:

$$
\left|\frac{\phi_{1}+\phi_{2}}{2 \Upsilon}\right|<1
$$

In the simulations we take $\Upsilon=1.05, \beta=500$. Fig. 4 shows the long-run values of the variable $X$ against $\theta$. We show these for two different sets of values for parameters $\phi_{1}$ and $\phi_{2}$. The left-hand side panel shows the case where $x=0$ is a locally stable equilibrium for $\theta=0$, while the right hand side panel shows that for slightly different values of $\phi_{1}$ and $\phi_{2}$, $x=0$ corresponds to a locally unstable equilibrium for $\theta=0$. Instead, two new locally stable equilibria have appeared on either side of $x=0$.

In the next section we will estimate the model for the US and the Netherlands. In both cases we will see that the values assumed for $\phi_{1}$ and $\phi_{2}$ here are not very different to what the data justifies. It is therefore possible that small shocks in the way people form expectations

\footnotetext{
${ }^{5}$ The results reported are for $\delta=1$, but we will also include later these results in which $\delta$ is estimated freely.

${ }^{6}$ The results reported use log-difference between house prices and fundamental price as value of $X_{t}$, that is, $X_{t}=\ln P_{t}-\ln \tilde{P}_{t}$, rather than the formula in Definition $3, X_{t}=\frac{P_{t}}{\tilde{P}_{t}}-1$. This will be updated in later versions of this research paper. The difference between the two measures is typically small.
} 

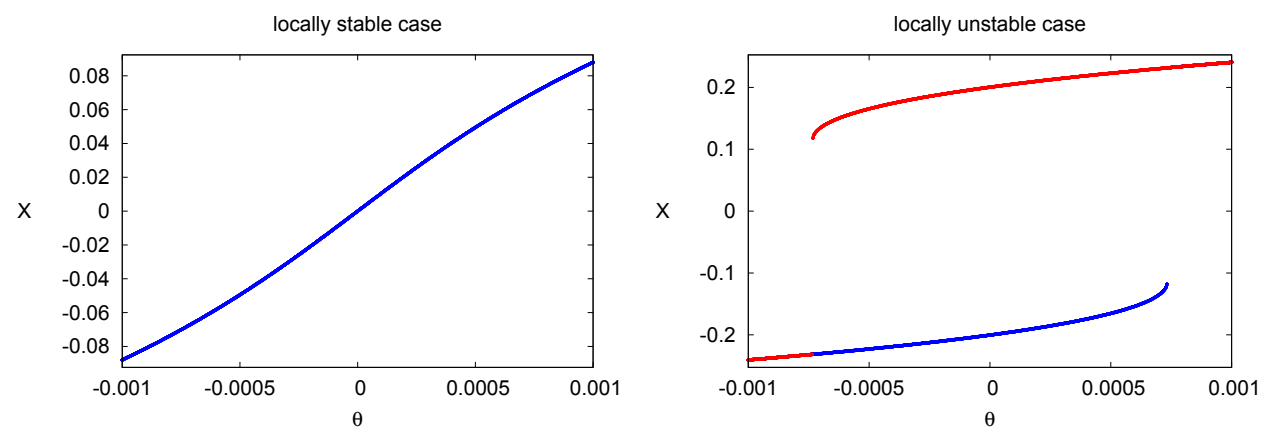

Figure 4: Bifurcation diagram. Belief parameters: $\phi_{1}=0.94, \phi_{2}=1.14$ (left panel) $\phi_{1}=0.96$, $\phi_{2}=1.16$ (right panel).

can lead to the fundamental price being a locally unstable equilibrium of house prices, while there are stable equilibria on either side of the fundamental price.

\section{Empirical results}

In what follows we estimate the two-type heterogenous beliefs BHM model and present the results for the housing market of the US and the Netherlands. We use an OECD housing dataset as described in Rousová and Van den Noord (2011), which contains quarterly data for nominal and real house prices as well as price-to-rent ratios from 1970Q1 to 2010Q4 (see Appendix for more details).

\subsection{The US Housing Market}

Fig. 5 presents the US house price index with its estimated fundamental value (left panel) and the log-difference between the two (right panel). We see that house prices have been increasing rapidly since the mid-1990s and have peaked around 2008. For the period after that, the model shows that house prices, even though on a declining path, have remained above the fundamental value.

We then ask whether the Scheffer model of critical transitions presented in Section 2 could identify abrupt shifts. Fig. 6 presents the same pictures as in Figs 17-18 for US house prices. We see that both the standard deviation and the $\operatorname{AR}(1)$ coefficient are increasing prior to the start of the house price decline but the measures do not capture a pattern that is identifiably different than other occurrences in the sample. 

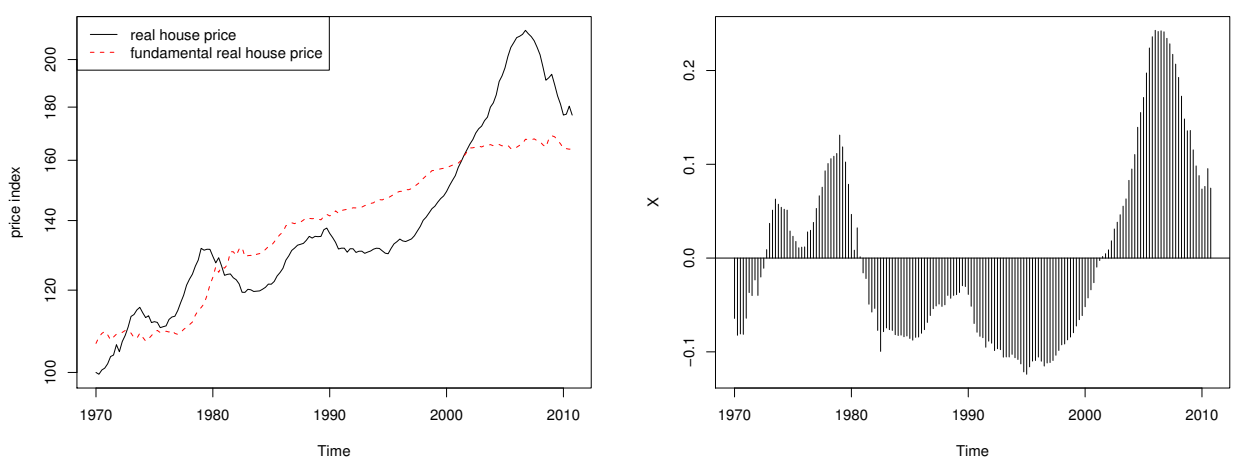

Figure 5: US: house price index $(1970 \mathrm{Q} 1=100)$ and the estimated fundamental price index (left) and their log-difference (right)

\section{Parameter estimates for heterogenous agents model}

Table 1 shows the estimated results for the period considered. The values for $\phi_{1}$ and $\phi_{2}$ are estimated to be 0.892 and 1.130, and more importantly are significantly different from each other. The data therefore confirms the presence of time-varying heterogeneity in the way that agents form expectations.

Table 1: Estimates for the US housing market, 1970-2010

\begin{tabular}{r|ccc}
\hline \hline & Estimate & Standard Error & $\operatorname{Pr}(>|t|)$ \\
\hline$\phi_{1}$ & 0.892 & 0.059 & $<2 e-16^{* * *}$ \\
$\phi_{2}$ & 1.130 & 0.069 & $<2 e-16^{* * *}$ \\
$\beta$ & 2716 & 3463 & 0.434 \\
$\theta$ & 0.0012 & 0.0009 & 0.189 \\
$\Upsilon$ & 1.010 & 0.015 & $<2 e-16^{* * *}$ \\
\hline \hline
\end{tabular}

Note: Signif. codes: $0{ }^{* * *}, 0.001^{* *}, 0.01^{\prime *} ;$ Residual standard error: 0.01104 (156 degrees of freedom)

We also find that $\theta$ is not significantly different than zero. The ratio on the left-hand-side of the stability condition (9) is estimated to be $\left|\frac{\hat{\phi}_{1}+\hat{\phi}_{2}}{2 \Upsilon}\right|=1.0010$, which implies that the system is just in the unstable regime.

\section{Estimated time-dependent fractions (US)}

Fig. 7 plots the log-difference between house prices and fundamental (upper panel), the proportion $n_{1}$ of agents forming expectations of type 1 associated with $\phi_{1}<1$ (middle panel), in other words, those agents who expect a return to the fundamentals, and finally the AR(1) coefficient (lower panel). 

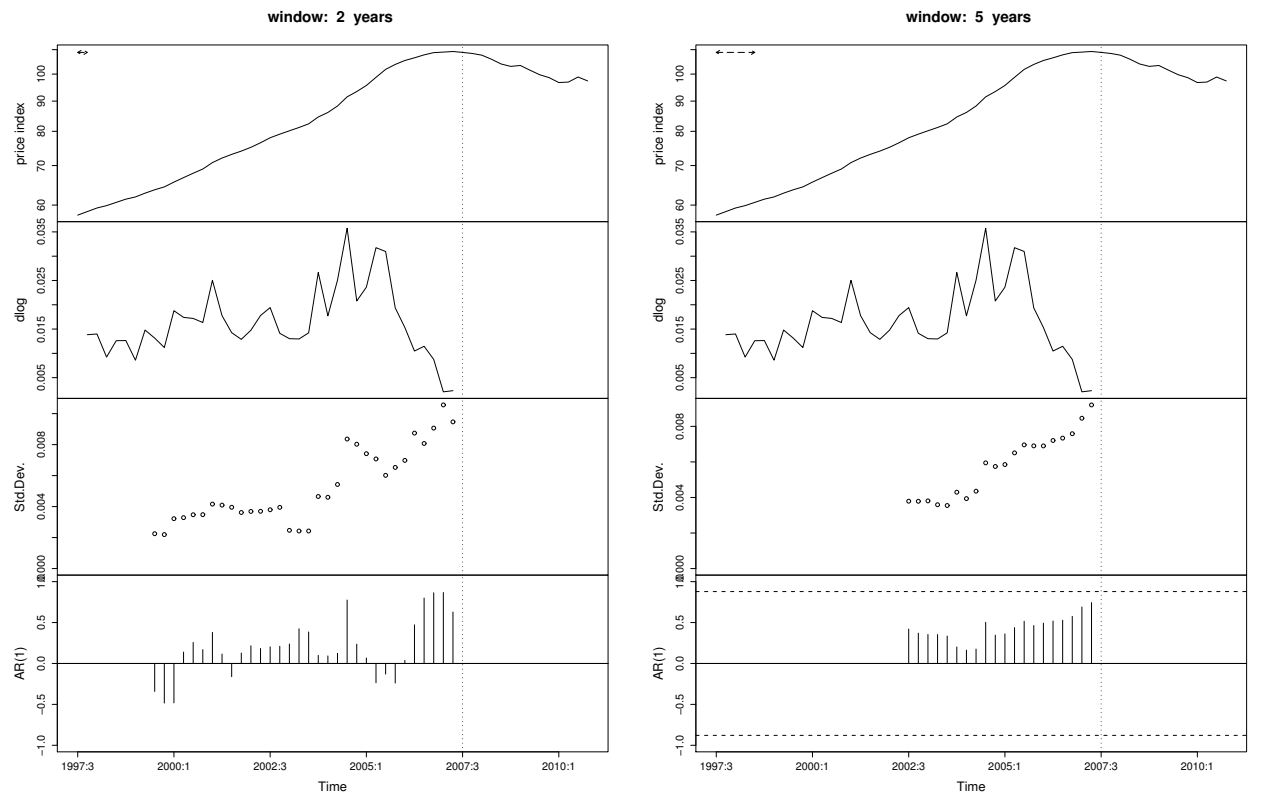

Figure 6: Results for US: Scheffer method

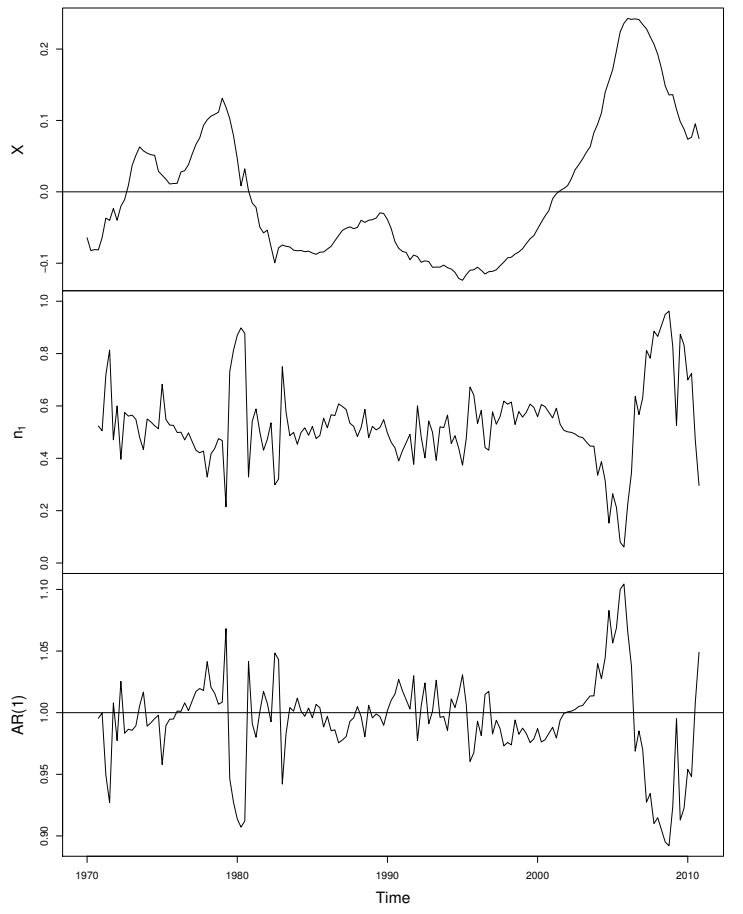

Figure 7: Results for US: estimated proportions and AR(1) coefficient 

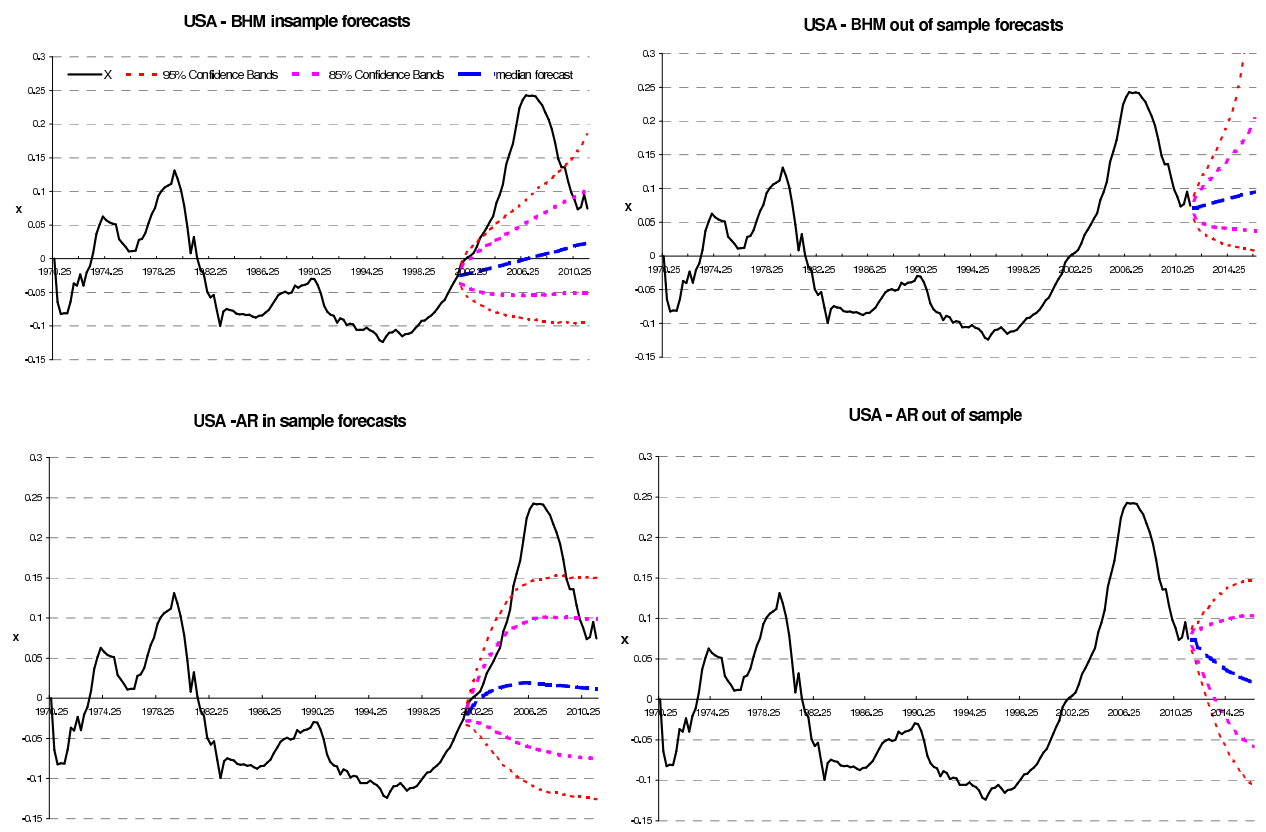

Figure 8: Fancharts for US data: estimates of the 5, 15, 50, 85 and $95 \%$ quantiles of the density forecasts (dashed lines) based on the BHM model (top panels) and an AR(5) model (lower panels). The deviation from the fundamental, is represented by the red solid lines.

We see that there is time-varying volatility in the way that agents form expectations. Around 2007, $n_{1}$ is estimated to be very small, implying that most agents agreed that house prices would continue to deviate from the fundamental value. This contributed to actual house prices being persistently above the fundamental price, a fact that we associate with the existence of a bubble. Around 2009, $n_{1}$ is very close to one; in other words, agents agree that prices will return to their fundamental price.

\section{Fancharts for the US}

We examine next how the heterogenous agents model forecasts, by comparison to a linear AR benchmark model.

Fig. 8 provides quantiles of density forecasts constructed for both models. The dashed lines correspond to estimates of the 5, 15, 50, 85 and $95 \%$ quantiles of the density forecasts, based on the BHM model (top panels) and an AR(5) model (lower panels). The AR order of 5 was used to ensure that both models have the same number of parameters. The variable of interest, the deviation from the fundamental, is represented by the red solid lines. The left hand side panels shows in-sample forecasts for the last 10 years of data. The right-hand-side panels correspond to 5-year ahead out-of sample forecasts starting at the end of the data-set (2010Q4). We observe that the density forecasts are qualitatively different. In particular, we see that the BHM model predicts the over-valuation to resume, even after the peak of a 

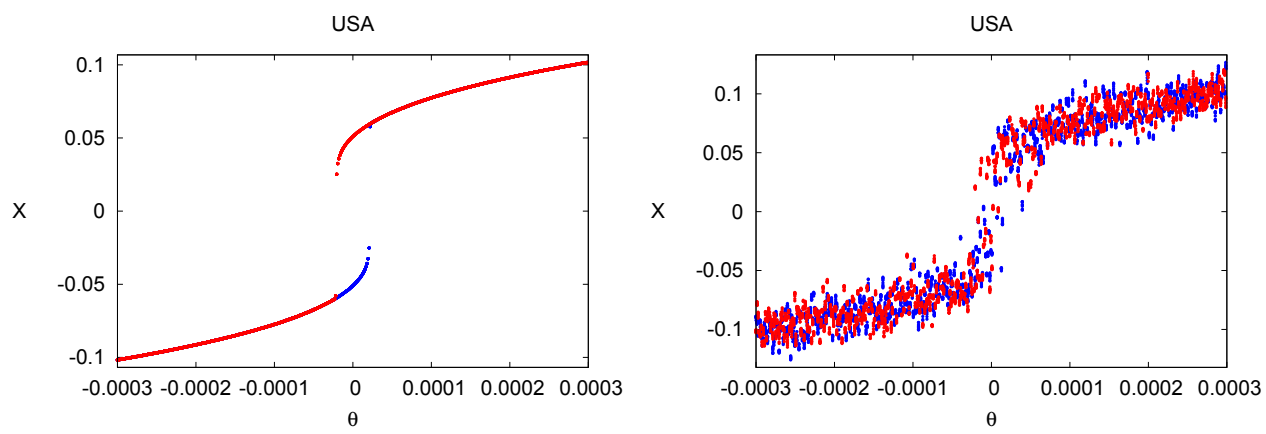

Figure 9: Results for US: multiple equilibria, noise and bifurcation

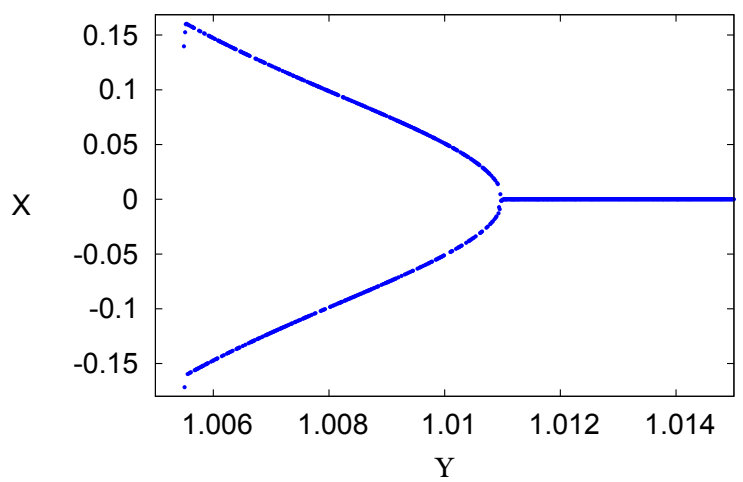

Figure 10: Results for US: Pitchfork bifurcation

bubble, while the AR(5) model predicts a progressive convergence of prices to its fundamental.

\section{Multiple equilibria}

The left panel of Fig. 9 assumes no shocks and shows simulations on how a slowly varying $\theta$ can induce critical transitions between two attractors. When we allow for small shocks (the size of which is a 10th of the estimated noise), we see that indeed the actual noise overwhelms the dynamics, such that we have early transitions and/or repetitive jumps between two stochastic attractors (right graph). We also performed similar simulations as a function of the parameter $\Upsilon$. The results are shown in Fig. 10. The simulations produce what is known as a pitchfork bifurcation. For the estimated value of $\Upsilon=1.010$ the system has two stable equilibria, which diverge as this value decreases. If however, it increases slightly above this value it produces a stable system with one equilibrium.

\subsection{The Dutch housing market}

We repeat the same exercise for the Dutch housing market. 

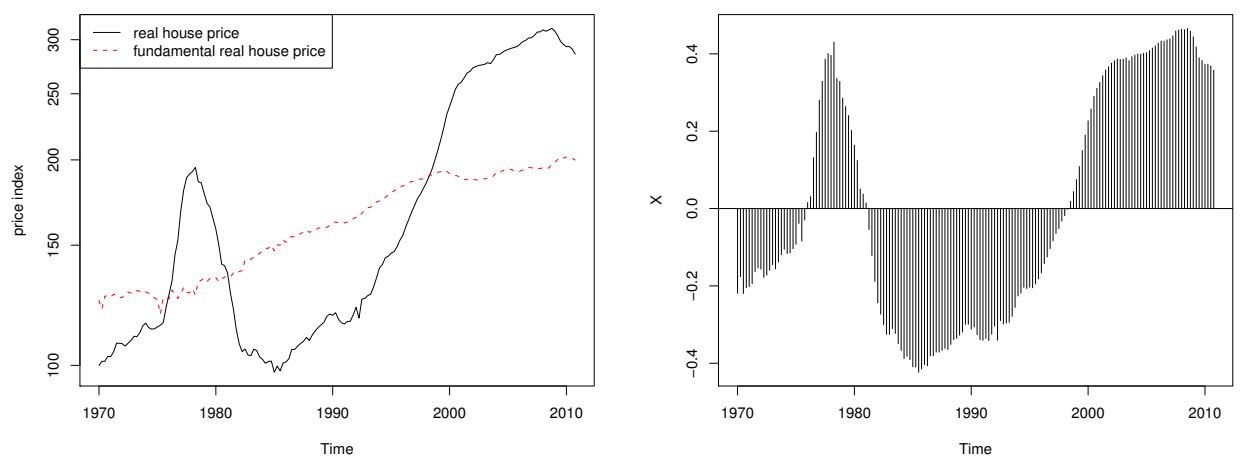

Figure 11: The Netherlands: House price index $(1970$ Q1=100) and the estimated fundamental value (left) and their log-difference (right)

Fig. 11 shows the evolution of house prices and the fundamental as well as their logdifference. We see that since the end of the 1990s, housing prices have been above the fundamental and it is only very recently that they have started coming back. They do remain however a long way away from what would be identified with equilibrium prices. This follows however a period of almost 20 years, starting in the early 1980s when prices were below the fundamental value.

We examine then whether the Scheffer et al.'s method captures these transitions, shown in Fig. 12. We see that again, neither the value of the standard deviation nor the $\operatorname{AR}(1)$ coefficient are good indicators of a transition that is about to happen.

\section{Parameter estimates for heterogenous agents model}

Table 2 shows the estimated results for the period considered. The values for $\phi_{1}$ and $\phi_{2}$ are estimated to be 0.9849 and 1.040, and more importantly are significantly different from each other. Just like in the US case, the data does confirm the presence of time-varying heterogeneity in the way that agents form expectations.

The value of $\Upsilon$ is fixed to 1.01 because when we estimate it freely we get unrealistically large values (1.51). We estimate the bias in expectations $(\theta)$ not be statistically different than zero. The stability condition for the system is then identified with $\left|\frac{\hat{\phi}_{1}+\hat{\phi}_{2}}{2 \Upsilon}\right|=1.0024$, which implies that the system is just in the unstable regime.

\section{Estimated time-dependent fractions (NL)}

Fig. 13 plots the log-difference between housing price and its fundamental value (upper panel), the proportion $n_{1}$ of agents forming expectations of type 1 associated with $\phi_{1}<1$ (middle 

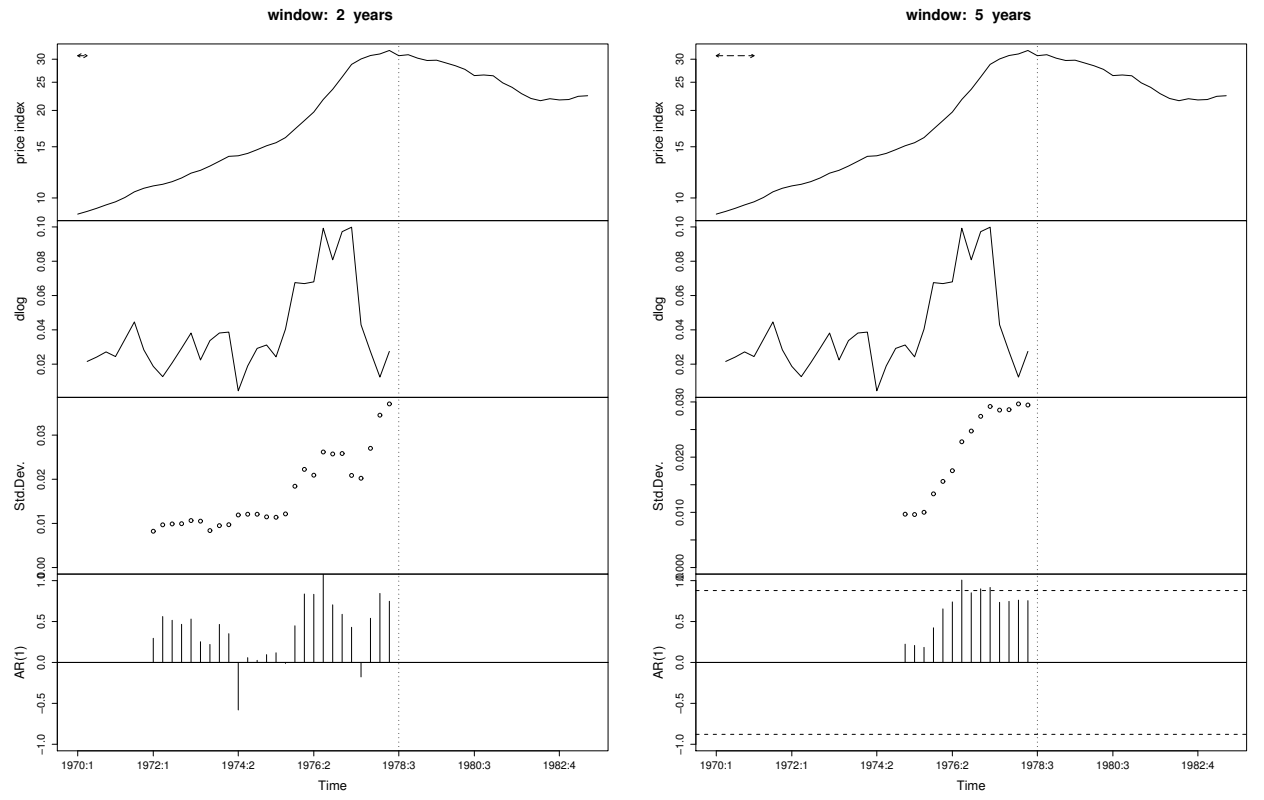

Figure 12: Results for NL: Scheffer method

Table 2: Estimates for the NL housing market, 1970-2010

\begin{tabular}{r|ccc}
\hline \hline & Estimate & Standard Error & $\operatorname{Pr}(>|t|)$ \\
$\phi_{1}$ & 0.9849 & 0.01495 & $2 e-16^{* * *}$ \\
$\phi_{2}$ & 1.040 & 0.01576 & $2 e-16^{* * *}$ \\
$\beta$ & 12420 & 21050 & 0.556 \\
$\theta$ & 0.00299 & 0.002071 & 0.151 \\
$\Upsilon$ & 1.01 & - & - \\
\hline \hline
\end{tabular}

Note: Signif. codes: $0^{\prime * * *}, 0.001^{{ }^{* *},} 0.01^{{ }^{*}}{ }^{\prime}$; Residual standard error: 0.0259 (157 degrees of freedom)

panel), the agents expecting a return to the fundamentals, and finally the AR(1) coefficient (lower panel).

We see that there is considerable more volatility in the way that agents form expectations by comparison to the US. Agents appear to be more keen to change the way they form expectations. It is not easy to see which period we could identify with a bubble, although we see that at the start of the period when prices started being above the fundamental price, at the end of the 1990s, almost all agents were predicting that this will continue to remain so $\left(n_{1}\right.$ very close to zero). 


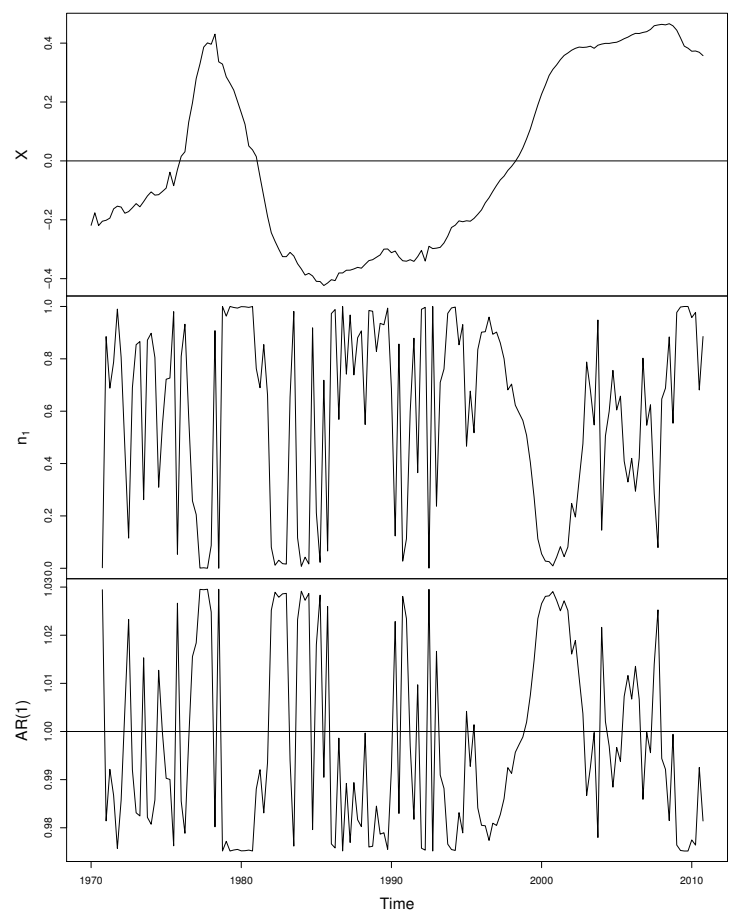

Figure 13: Results for NL: estimated proportions and AR(1) coefficient

\section{Fancharts for the Netherlands}

We examine next how the heterogenous agents model forecasts, by comparison to a linear AR benchmark model.

Fig. 14 provides quantiles of density forecasts constructed for both models. The dashed lines correspond to estimates of the 5, 15, 50, 85 and 95\% quantiles of the density forecasts, based on the BHM model (top panels) and an AR(5) model (lower panels). The AR order of 5 was used to ensure that both models have the same number of parameters. The variable of interest, the deviation from the fundamental, is represented by the red solid lines. The left hand side panels shows in-sample forecasts for the last 10 years of data. The right-hand-side panels correspond to 5-year ahead out-of sample forecasts starting at the end of the dataset (2010Q4). For the in-sample forecasts we see that the BHM model predicts that house prices will not be below fundamental prices. The AR model on the other hand does predict that prices can potentially be below the fundamental value. Similarly in the out-of-sample forecasts, the BHM model has again an upward bias, but more importantly, its mean forecast predicts a divergence in prices from the fundamental, whereas the AR model predicts a return to the fundamental price. 

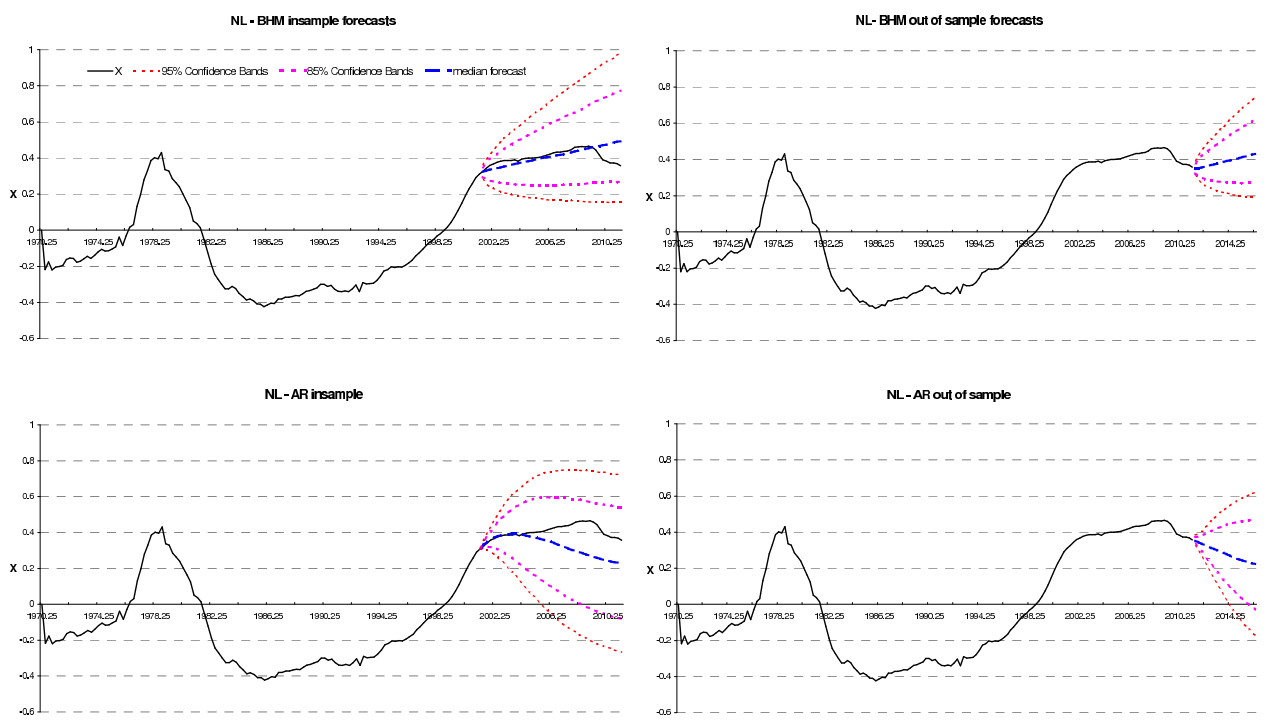

Figure 14: Fancharts for NL data: estimates of the 5, 15, 50, 85 and $95 \%$ quantiles of the density forecasts (dashed lines) based on the BHM model (top panels) and an AR(5) model (lower panels). The deviation from the fundamental, is represented by the red solid lines.
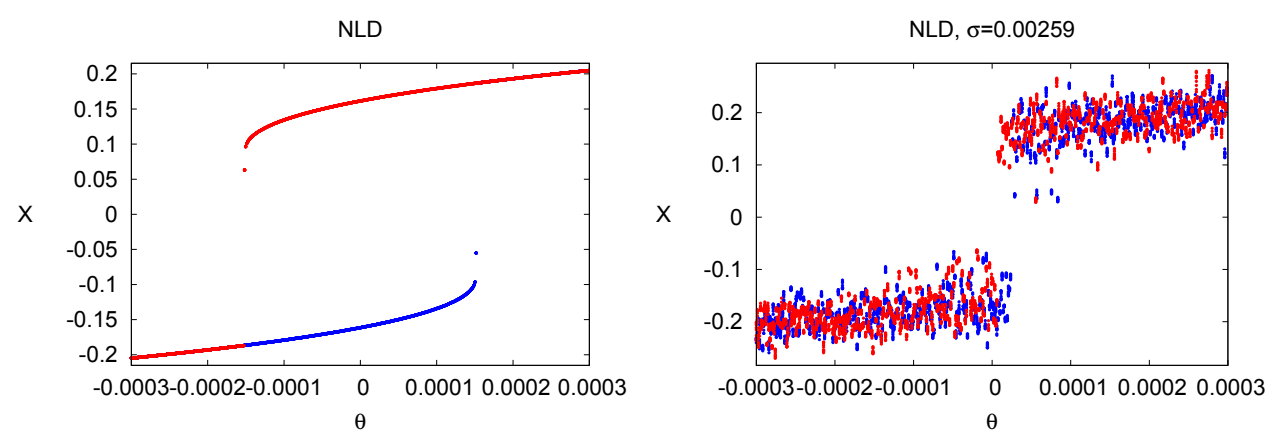

Figure 15: Results for NL: multiple equilibria, noise and bifurcation

\section{Multiple equilibria}

The left graph of Fig. 15 shows simulations on how a slowly varying $\theta$ can induce critical transitions, absent of shocks. When we introduce shocks (even very small ones, a 10th of the estimated noise), we see that indeed the actual noise overwhelms the dynamics such that we have early transitions and/or repetitive jumps between two stochastic attractors (right graph).

Similarly we repeat the exercise for the discount factor $\Upsilon$ shown in Fig. 16. The value for the discount factor is set equal to that estimated for the US at 1.01. We see the same pitchfork bifurcation as in the US. 


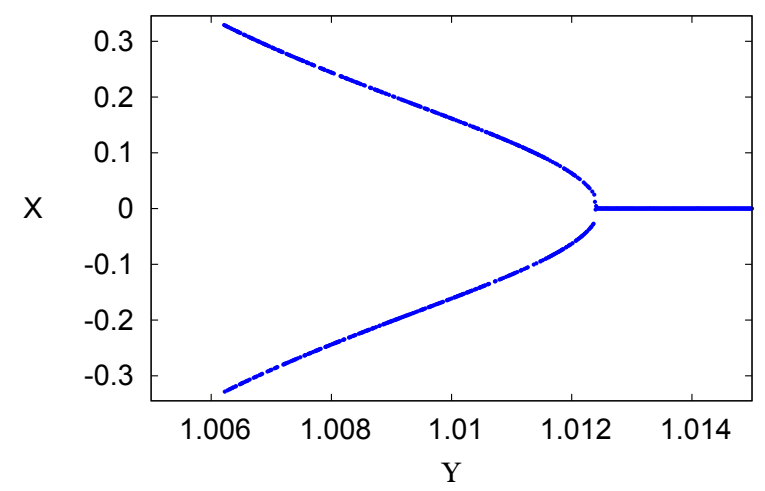

Figure 16: Results for NL: Pitchfork bifurcation

\section{Summary/conclusions}

In this paper we ask whether we can use statistical, a-theoretical models to foresee abrupt changes in economic series. We borrow from the critical transitions literature, and in particular from the technique put forward by Scheffer et al. (2009). In our estimations, we observe no discernible critical slowdown as soon as critical points are approached, in any way that it could provide an early warning. Our intuition tells us that the stochastic nature of economic systems is the reason for this. Noise plays a very important role, in that it induces shifts when multiple attractors exist, before these statistical methods are allowed to take the threshold values mentioned. In this respect, the attractors found play the role of sticky states, where the system tends to spend more time. Due to this, we then turned to a model-based approach to predict regime shifts. To this end we have applied a heterogenous agents model, where agents have heterogeneous and time-varying beliefs about future state variables. This approach falls in the category of boundedly rational models but it does require that the form of agents' beliefs is specified. The important feature of such an approach is that it does allow for multiple equilibria and we can experiment with the conditions which cause the shift between them. Our estimations, in particular the large estimated noise levels, do explain why the regimes shifts cannot be detected in a clear cut way using Scheffer's approach.

Nevertheless, we believe that these models help us make the following case. First, the data do justify the existence of multiple beliefs. It is true that the form of expectations is assumed but the data does capture significant (statistically and economically) differences in the way that people believe prices will revert to fundamentals. This is qualitatively a very different model than the traditional RE models where agents are both homogenous and are bound by the steady state. Second, the exact parameterization of these beliefs can make a difference between having a stable or unstable system. It would be important then to have precise estimates of these values. Third, using these non-linear models to forecast does lead 
to very different predictions by comparison to the benchmark linear model. It would therefore be very important to identify reliable criteria according to which to rank these models. 


\section{References}

[1] Abiad, A. (1999). Early Warning Systems For Currency Crises: A Markov-Switching Approach with Application to Southeast Asia. Manuscript, University of Pennsylvania, Philadelphia.

[2] Arias, G and U. Erlandsson (2005). Regime switching as an alternative early warning system of currency crises - an application to South-East Asia. CEFI Working Paper 0502 .

[3] Ambrose, B.W, P. Eichholtz, T.Lindenthal, (2011). House Prices and Fundamentals: 355 Years of Evidence, Manuscript.

[4] Berg, A. Borensztein, E. and Pattillo C. (2005). Assessing Early Warning Systems: How Have They Worked in Practice? IMF Saff Papers 52 (3) 462-502.

[5] Berg, A., Pattillo, C. (1999). Predicting currency crises: the indicators approach and an alternative. Journal of International Money Finance, 18, 561-586.

[6] Boswijk, H.P, C.H. Hommes, S. Manzan (2007). Behavioral Heterogeneity in Stock Prices, Journal of Economic Dynamics and Control, 31, 1938-1970.

[7] Brock, W.A., and C.H.Hommes (1998). Heterogeneous Beliefs and routes to chaos in a Simple Asset Pricing Model. Journal of Economic Dynamics and Control, 22, 1235-1274.

[8] Burnside, C. M. Eichenbaum and S. Rebelo, (2011). Understanding Booms and Busts in Housing Markets, mimeo

[9] Campbell, Sean D.; Davis, Morris A.; Gallin, Joshua, and Robert F. Martin. (2009). "What moves housing markets: A trend and variance decomposition of the rentprice ratio." Journal of Urban Economics, 66(2): 90-102.

[10] Davis, E.P. and Karim, D. (2008a). Comparing early warning systems for banking crises. Journal of Financial Stability 4, 89-120.

[11] Davis, E.P. and Karim, D. (2008b). Could early warning systems have helped to predict the subprime crisis? National Institute Economic Review 206, 35-47.

[12] Demirgüç-Kunt, A. and Detragiache, E. (2005). Cross-Country Empirical Studies of Systemic Bank Distress: A Survey, IMF Working Paper 05/96.

[13] Ditlevsen, P.D. and Johnsen, S.J. (2010). Tipping points: Early warning and wishful thinking. Geophysical Research Letters 37, L19703, doi:10.1029/2010GL044486. 
[14] Franke, R. and Westerhoff, F. (2011). Structural stochastic volatility in asset pricing dynamics: Estimation and model contest, BERG Working Paper Series on Government and Growth 78, University of Bamberg.

[15] De Jong, E., Verschoor, W.F.C. and Zwinkels, R.C.J. (2009). Behavioural heterogeneity and shift-contagion: Evidence from the Asian crisis. Journal of Economic Dynamics and Control 33, 1929-1944.

[16] De Jong, E., Verschoor, W.F.C. and Zwinkels, R.C.J. (2010) Heterogeneity of agents and exchange rate dynamics: Evidence from the EMS, Journal of International Money and Finance 29, 1652-1669.

[17] Hamilton, J.D. (1994). Time Series Analysis. Princeton University Press, Princeton.

[18] Himmelberg, C., C.Mayer and T.Sinai (2005). Assessing High House Prices: Bubbles, Fundamentals and Misperceptions, Journal of Economic Perspectives, 19(4), 64-92.

[19] Hott C. and Monnin, P. (2008). Fundamental Real Estate Prices: An Empirical Estimation with International Data, The Journal of Real Estate Finance and Economics, Springer, 36(4), 427-450.

[20] Kaminsky, G. Lizondo, S. and Reinhart, C. (1998). Leading indicators of currency crises. International Monetary Fund Staff Papers 45, 1-48.

[21] Kouwenberg, R. and R.C.J. Zwinkels, (2011). Chasing Trends in the U.S. Housing Market, manuscript, February.

[22] Leamer, E. E., (2007). Housing IS the Business Cycle, NBER Working Paper No. 13428, September.

[23] Lux, T. (2009). Rational forecasts or social opinion dynamics? Identification of interaction effects in a business climate survey, Journal of Economic Behavior and Organization 72, $638-655$.

[24] Oh, K.J., Kim, T.Y. and Kim, C. (2006). An early warning system for detection of financial crisis using financial market volatility. Expert Systems 23, 83-98.

[25] Poterba, J.M. (1992). Taxation and Housing: Old Questions, New Answers, American Economic Review, 82, 237-242.

[26] Rousová, L. and P. van den Noord (2011). Predicting Peaks and Troughs in Real House Prices. OECD Economics Department Working Papers, No. 882. 
[27] Scheffer, M. (2009). Critical transitions in nature and society, Princeton Studies in Complexity, Princeton University Press, Princeton, NJ.

[28] Scheffer, M., Bascompte, J., Brock, W.A., Brovkin, V., Carpenter, S.R., Dakos, V., Held, H., van Nes, E.H., Rietkerk, M. and Sugihara, G. (2009). Early-warning signals for critical transitions. Nature 461, 53-59.

[29] Thompson, J.M.T. and Sieber, J. (2011). Climate tipping as a noisy bifurcation: a predictive technique, IMA Journal of Applied Mathematics (2011) 76, 27-46.

[30] Van den Berg, J. Candelon, B. and Urbain, J.-P. (2008). A cautious note on the use of panel models to predict financial crises, Economics Letters 101, 80-83. 


\section{Appendix}

\subsection{Graphs: Examples of potential regime shifts in finance}
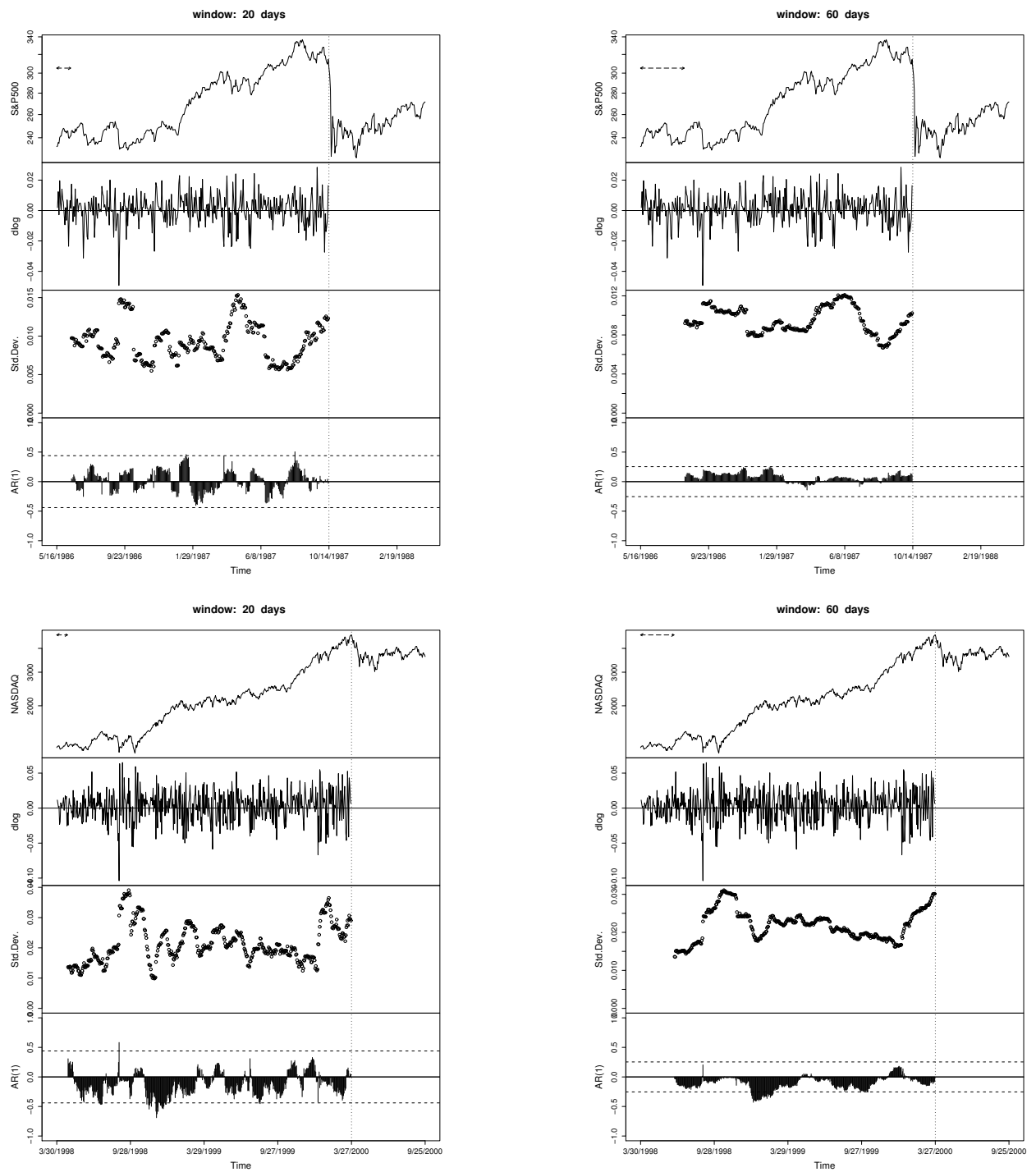

Figure 17: Price, log-return, time-varying standard deviation and AR(1)-coefficient; upper panel: 1987 crash, S\&P 500 index; lower panel: dot.com bubble burst, NASDAQ index 

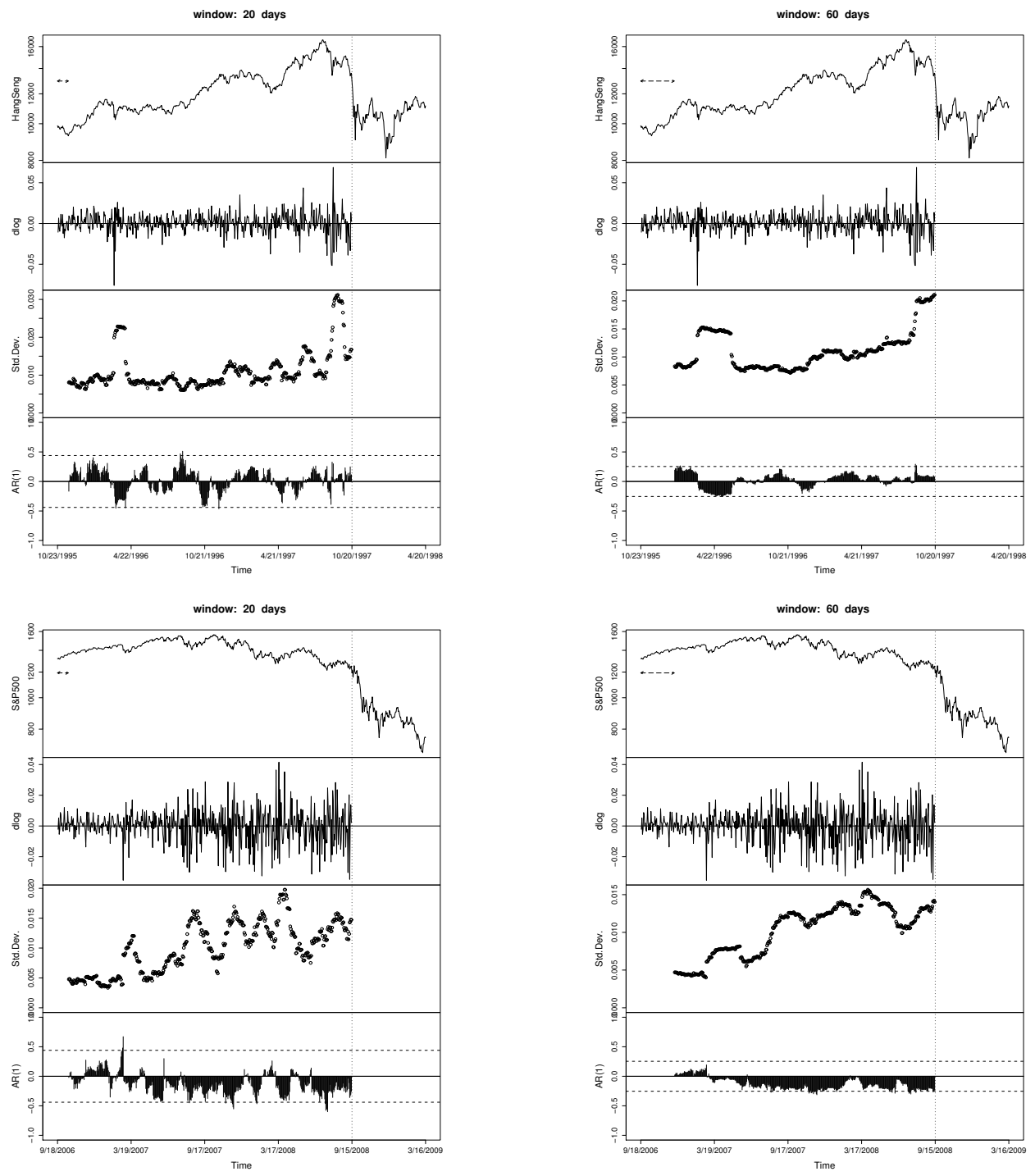

Figure 18: Price, log-return, time-varying standard deviation and AR(1)-coefficient; upper panel: Asian crisis, HangSeng index; lower panel: Collapse Lehman Bros, S\&P 500 index 


\subsection{Data}

We use an OECD housing dataset as described in Rousová and Van den Noord (2011). For 20 countries (including the US and the Netherlands) this dataset contains quarterly data for nominal and real house prices from 1970.1 to 2010.4 (see Rousová and Van den Noord (2011), OECD Economics Department Working Papers No. 882, Appendix 1-2, page 22-23, for the list of countries and corresponding data sources). The nominal house price is indexed using 2005 as base year. The real house price index is derived by deflating with the private final consumption expenditure deflator, available from the OECD Economic Outlook 89 database. The priceto-rent ratio is defined as the nominal house price index divided by the rent component of the consumer price index, made available by the OECD. Long term interest rates are also retrieved from the OECD Economic Outlook 89 database. 